\title{
PERCEPÇÃO DOS CONSUMIDORES DE PRODUTOS DE ORIGEM ANIMAL DE LAVRAS - MINAS GERAIS, BRASIL, EM RELAÇÃO AO SERVIÇO DE INSPEÇÃO E SEGURANÇA DOS ALIMENTOS
}

(CONSUMERS PERCEPTIONS OF ANIMAL PRODUCTS OF LAVRAS - MINAS GERAIS, BRAZIL, IN RELATION TO THE INSPECTION SERVICE AND FOOD SAFETY)

\section{N. A. AMBRÓSIO ${ }^{1}$, T. F. SILVA ${ }^{1}$, J. M. BARBIERI ${ }^{1}$, M. F. M. ROCHA ${ }^{2}$, G.M. COSTA ${ }^{3}$, C. M. B. ROCHA ${ }^{3}$}

Com o objetivo de caracterizar os consumidores de produtos de origem animal (POA) na cidade de Lavras, Minas Gerais conforme suas percepções em relação ao serviço de inspeção de POA e conceitos sobre segurança dos alimentos foi elaborado um formulário de entrevista com questões objetivas e dissertativas referentes à condição social, grau de escolaridade, conhecimento da importância do serviço de inspeção e de possíveis doenças veiculadas por POA. Os locais de aplicação das entrevistas foram selecionados por amostragem aleatória simples entre os supermercados de maior representatividade no município. Utilizou-se uma amostra de 101 consumidores, que foram abordados aleatoriamente, de ambos os sexos e com idade superior a 18 anos de idade. Os resultados foram obtidos através de uma análise descritiva dos dados coletados. Foi observado um desconhecimento a respeito do serviço de inspeção de POA (76\%), assim como da atuação do Médico Veterinário na preservação da saúde de tais consumidores (85\%). Embora 92\% dos entrevistados demonstrem um conhecimento referente às possíveis doenças transmitidas por alimentos de origem duvidosa, quando foram questionados em relação às vantagens em consumir um produto de origem animal inspecionado, $23 \%$ afirmaram não saber sobre tais vantagens, ou relacionaram com a qualidade do produto (28\%) e segurança dos alimentos (36\%). Como qualidade do produto, os consumidores entendem como sendo aqueles alimentos dentro do prazo de validade, não sendo comercializados deteriorados, podendo assim oferecer algum risco a sua saúde. Em relação à segurança dos alimentos eles alegaram como sendo a garantia de uma adequada procedência destes produtos certificados. Diante desta realidade se faz necessário um trabalho de conscientização junto aos consumidores, enfatizando a importância da certificação sanitária e as possíveis doenças de caráter zoonótico transmissíveis por POA.

\section{APOIO: CNPq e FAPEMIG}

1 - Mestrando em Ciências Veterinárias pela Universidade Federal de Lavras - UFLA, Lavras - MG.

2 - Graduanda em Medicina Veterinária pela Universidade Federal de Lavras-UFLA, Lavras - MG

3 - Professor Adjunto do Departamento de Medicina Veterinária da Universidade Federal de Lavras-UFLA, Lavras - MG

*Autor para correspondência: natalia_ambrosio@posgrad.ufla.br 